\title{
Fabrication of Alumina-Doped Optical Fiber Preforms by an MCVD-Metal Chelate Doping Method
}

\author{
K. A. Mat Sharif ${ }^{1}$, N. Y. M. Omar ${ }^{2}{ }^{\oplus}$, M. I. Zulkifli ${ }^{1}$, S. Z. Muhamad Yassin ${ }^{1}$ and \\ H. A. Abdul-Rashid $2, *$ (iD \\ 1 Telekom Malaysia Research \& Development Sdn. Bhd., Cyberjaya 63000, Malaysia; \\ khairulmcvd@gmail.com (K.A.M.S.); mohdimran@tmrnd.com.my (M.I.Z.); \\ shahrinzen@tmrnd.com.my (S.Z.M.Y.) \\ 2 Fiber Optics Research Center, Faculty of Engineering, Multimedia University, Cyberjaya 63100, Malaysia; \\ nasr-omar@hotmail.com \\ * Correspondence: hairul@mmu.edu.my
}

Received: 28 August 2020; Accepted: 10 October 2020; Published: 16 October 2020

Featured Application: Fabrication of rare-earth-doped fiber amplifiers and high-power fiber lasers.

\begin{abstract}
This paper reports on the fabrication of alumina-doped preforms using a modified chemical vapor deposition (MCVD)-vapor phase chelate delivery system with $\mathrm{Al}(\mathrm{acac})_{3}$ as the precursor. The objectives of this work are to study the deposition process, the efficiency of the fabrication process, and the quality of the fabricated fiber preforms. Two parameters are studied, the $\mathrm{Al}(\mathrm{acac})_{3}$ sublimator temperature $\left(\mathrm{T}_{\mathrm{Al}}{ }^{\circ} \mathrm{C}\right)$ and the deposition direction (i.e., downstream and upstream). Other parameters such as the oxygen flow and deposition temperature are fixed. The results show that high uniformity of the refractive index difference $(\% \mathrm{RSD}<2 \%)$ and core size $(\% \mathrm{RSD}<2.4 \%)$ was obtained along the preform length using downstream deposition, while for the combined upstream and downstream deposition, the uniformity deteriorated. The process efficiency was found to be about $21 \%$ for $\mathrm{T}_{\mathrm{Al}}{ }^{\circ} \mathrm{C}$ of $185^{\circ} \mathrm{C}$ and downstream deposition. From the EDX elemental analysis, the refractive index was found to increase by 0.0025 per mole percent of alumina.
\end{abstract}

Keywords: MCVD (Modified Chemical Vapor Deposition); chelate delivery system; $\mathrm{Al}(\mathrm{acac})_{3}$; alumina; vapor phase doping; EDX (X-ray spectroscopy)

\section{Introduction}

Alumina $\left(\mathrm{Al}_{2} \mathrm{O}_{3}\right)$ is an interesting dopant material for silica optical fiber technology. It does not only function as a refractive index raiser but also helps dissolve other co-dopants such as rare-earth elements in the silica matrix. Thus, alumina is very essential to the fabrication of rare-earth-doped fiber amplifiers and high-power fiber lasers. The use of alumina was first reported by Maurer and Schultz [1] in 1972 for passive fiber applications, followed by Simpson and Macchesney [2], Ohmori et al. [3], Roba [4], Wang et al. [5,6], and Čampelj et al. [7]. The fabrication techniques used were outside vapor deposition (OVD), vertical axial deposition (VAD), and modified chemical vapor deposition (MCVD). With the rapid progress on rare-earth specialty fibers, more research is being focused on incorporating alumina in silica, particularly by the MCVD method. The most common technique for doping alumina is conventional MCVD with solution doping (non-vapor phase) (e.g., [8]). This technique has been very successful in the fabrication of fiber amplifiers such as erbium-doped fiber (EDF). However, the technique suffers from limitations, including the inability to deliver advanced fiber design requirements such as high dopant concentration, large core, and precise wave guiding structure. 
Furthermore, due to the nature of the MCVD solution doping process that involves several stages, it tends to degrade the quality of the preform or fiber.

Another alternative technique is MCVD with a chelate delivery system, which was first reported by Tumminelli et al. [9]. This technique offers in situ vapor phase deposition of dopants in a controllable process, thus improving the quality of the fabricated preform or fiber. Since the study by Tumminelli et al., several research groups have reported on the use of MCVD with chelate delivery systems, e.g., [10-17]. In most of these studies, anhydrous aluminum chloride $\left(\mathrm{AlCl}_{3}\right)$ has been used as the precursor for alumina, with few using aluminum acetylacetonate $\left(\mathrm{Al}\left(\mathrm{C}_{5} \mathrm{H}_{7} \mathrm{O}_{2}\right)_{3} ; \mathrm{Al}(\mathrm{acac})_{3}\right)$ as a precursor, e.g., [16]. $\mathrm{AlCl}_{3}$ is commonly used due to its relatively high vapor pressure. In this paper, we report on the fabrication of alumina-doped preforms using $\mathrm{Al}(\mathrm{acac})_{3}$. Even though $\mathrm{Al}(\mathrm{acac})_{3}$ has lower vapor pressure than $\mathrm{AlCl}_{3}$, it exhibits some advantages over $\mathrm{AlCl}_{3}$, including its low cost, non-corrosive properties, and chemical stability. However, the conversion of $\mathrm{Al}(\mathrm{acac})_{3}$ to $\mathrm{Al}_{2} \mathrm{O}_{3}$ requires more oxygen (compared to $\mathrm{AlCl}_{3}$ ) in order to eliminate incomplete oxidation of $\mathrm{Al}(\mathrm{acac})_{3}$ which can lead to carbon contamination. The total gas flow rate (oxygen and carrier gas) $Q_{T}$ is thus considerably higher compared to that in the standard MCVD process. This entails the study of the chemistry and the deposition mechanism involved, as well as the effect of various process parameters on the deposition and incorporation efficiency of the $\mathrm{Al}_{2} \mathrm{O}_{3}$ particles formed during the process. In this work, we studied the fabrication process of alumina-doped silica fiber preforms with different $\mathrm{Al}(\mathrm{acac})_{3}$ sublimator temperature $\left(\mathrm{T}_{\mathrm{Al}}{ }^{\circ} \mathrm{C}\right)$ and deposition direction (i.e., downstream and upstream). Other parameters such as total oxygen flow, deposition temperature, carriage speed $\left(V_{b}\right)$, and spindle rotation were fixed. The aim is to achieve the highest possible doping amount of alumina, which, in turn, allows for greater incorporation of rare-earth elements into silica fibers. The fabricated preforms were checked for radial and longitudinal uniformity. The efficiency of the fabrication process was also determined by comparing the $\mathrm{Al}_{2} \mathrm{O}_{3}$ concentration obtained from energy-dispersive $\mathrm{X}$-ray spectroscopy (EDX) analyses with that derived theoretically. We are hopeful that the outcome of this study will add to the growing research concerning the MCVD-vapor phase fabrication of (highly) rare-earth-doped silica fibers for high-power fiber lasers and fiber amplifiers.

\section{Materials and Methods}

Our chelate delivery system is depicted in Figure 1. The $\mathrm{Al}(\mathrm{acac})_{3}$ is placed in a sublimator (maximum operating temperature of $220^{\circ} \mathrm{C}$ ), and the vapor is carried to the reaction zone by a constant flow of high-purity helium gas using heated stainless steel tubes. A ceramic heater is placed at the end of the delivery tube and just before the MCVD main oxyhydrogen burner in order to prevent any condensation of $\mathrm{Al}$ (acac) $)_{3}$ vapor on the walls of the glass substrate tube.

The fabrication process is divided into two major consecutive steps; first is the MCVD process, and second is the $\mathrm{Al}(\mathrm{acac})_{3}$ oxidation process. These steps are then followed by a standard MCVD procedure including sintering and collapsing of the glass substrate tube to a solid preform. At the MCVD step, a Heraeus F300 synthetic silica substrate tube (25mm (Outer Diameter), 19 mm (Inner Diameter)) is first rinsed with isopropanol/acetone to remove any organic contaminants. The tube is then mounted onto a glass working lathe and is etched with $\mathrm{SF}_{6}$ for several passes of the oxyhydrogen burner at a very high temperature. Several layers of high-purity $\mathrm{SiO}_{2}$ are then deposited and sintered to act as a barrier between the glass substrate tube and the preform's core. Finally, for the preform's core, two layers of unsintered $\mathrm{SiO}_{2}$ are deposited for doping with alumina. For the $\mathrm{Al}(\mathrm{acac})_{3}$ oxidation step, $\mathrm{Al}(\mathrm{acac})_{3}$ vapor is delivered to the glass substrate tube where it is converted to $\mathrm{Al}_{2} \mathrm{O}_{3}$ at high temperature and in the presence of high-purity oxygen gas. The deposition of the formed $\mathrm{Al}_{2} \mathrm{O}_{3}$ particles occurs on the surface of the deposited unsintered silica layers. Table 1 lists the process parameters used in this work. For Preform 1 (P1), $\mathrm{Al}(\mathrm{acac})_{3}$ was sublimed at $\mathrm{T}_{\mathrm{Al}}{ }^{\circ} \mathrm{C}$ of $175{ }^{\circ} \mathrm{C}$, with carrier gas $(\mathrm{He})$ and $\mathrm{O}_{2}$ flow rates of 1440 and $2400 \mathrm{sccm}$, respectively. The deposition temperature $\left(\mathrm{T}_{\mathrm{dep}}{ }^{\circ} \mathrm{C}\right)$ was fixed at $1850{ }^{\circ} \mathrm{C}$ with a carriage speed $\left(\mathrm{V}_{\mathrm{dep}}\right)$ of $100 \mathrm{~mm} / \mathrm{min}$ and spindle rotation of $50 \mathrm{rpm}$ (rotation per minute). A total of 10 layers were deposited in the downstream direction. For Preforms 2 (P2) and $3(\mathrm{P} 3), \mathrm{T}_{\mathrm{Al}}{ }^{\circ} \mathrm{C}$ 
was fixed at $185^{\circ} \mathrm{C}$, with $\mathrm{P} 2$ having a total of 8 layers deposited in the downstream direction and P3 having 7 layers deposited in each direction (i.e., downstream and upstream). Figure 2 illustrates the downstream and upstream deposition directions.

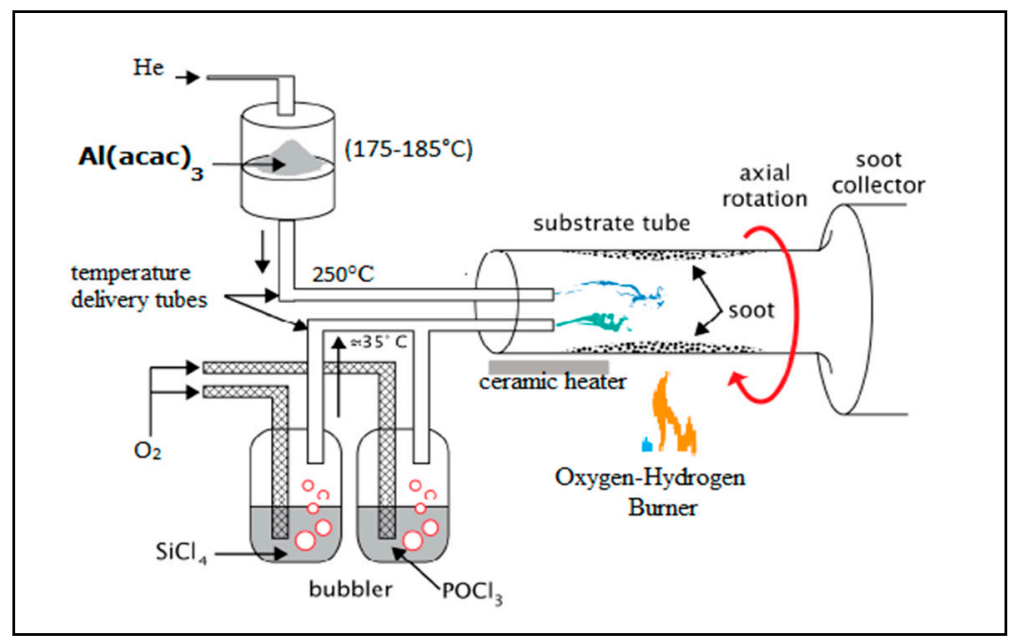

Figure 1. A schematic diagram for the modified chemical vapor deposition (MCVD)-chelate delivery system [14]. The $\mathrm{Al}(\mathrm{acac})_{3}$ is placed in a sublimator consisting of a stainless steel plate, a heater, and a gas system (outlet and inlet). The stainless steel delivery tube is equipped with a heater to prevent any $\mathrm{Al}(\mathrm{acac})_{3}$ vapor condensation. The standard MCVD delivery lines and the chelate delivery line are joined with a special rotary seal. A ceramic heater is placed just before the hot zone.

Table 1. Process parameters and calculated flow rates for the fabrication process.

\begin{tabular}{|c|c|c|c|c|c|c|c|c|}
\hline \multirow{2}{*}{ Preform } & \multirow{2}{*}{$\mathrm{T}_{\mathrm{Al}}\left({ }^{\circ} \mathrm{C}\right)$} & \multicolumn{2}{|c|}{ Gas Flow (sccm) } & \multirow{2}{*}{$\underset{(\mathrm{g} / \mathrm{min})^{1}}{Q_{v}}$} & \multirow{2}{*}{$\underset{(\mathrm{g} / \mathrm{min})^{1}}{Q_{m}}$} & \multicolumn{2}{|c|}{ Number of Passes } & \multirow{2}{*}{ Total $Q_{m}(\mathrm{~g})^{1}$} \\
\hline & & $\mathrm{He}$ & $\mathrm{O}_{2}$ & & & Forward & Backward & \\
\hline P1 & 175 & \multirow{3}{*}{1440} & \multirow{3}{*}{2400} & 0.062 & $0.97 \times 10^{-2}$ & 10 & - & 0.34 \\
\hline $\mathrm{P} 2$ & \multirow{2}{*}{185} & & & \multirow{2}{*}{0.116} & \multirow{2}{*}{$1.82 \times 10^{-2}$} & 8 & - & 0.58 \\
\hline P3 & & & & & & 7 & 7 & 1.02 \\
\hline
\end{tabular}

${ }^{1} \mathrm{~V}_{\text {dep }} 100 \mathrm{~mm} / \mathrm{min}, Q_{v}$ is the flow rate of reactant $(\mathrm{g} / \mathrm{min}), Q_{m}$ is the product's flow rate $(\mathrm{g} / \mathrm{min})$, and total $Q_{m}$ is the total amount of product during the process $(\mathrm{g})$. The vapor pressure for $\mathrm{Al}(\mathrm{acac})_{3}$ was taken from [18].

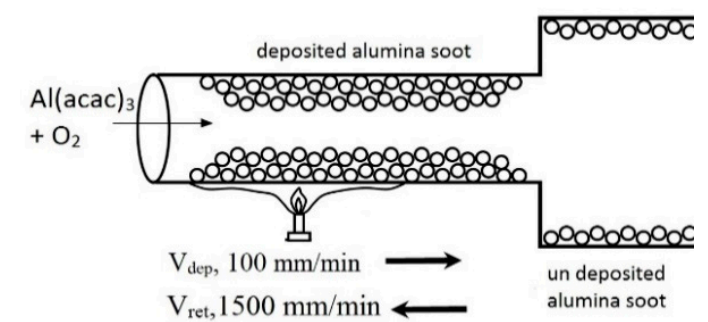

(a)

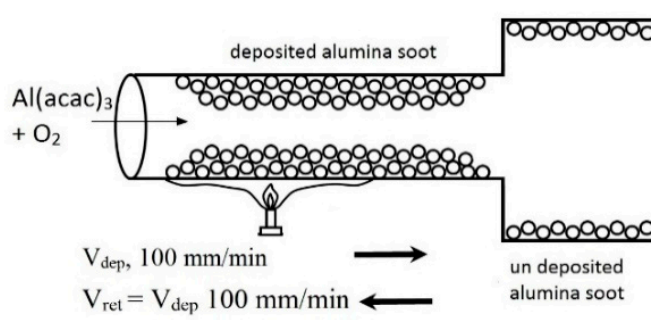

(b)

Figure 2. (a) The downstream deposition direction with $V_{\text {dep }} 100 \mathrm{~mm} / \mathrm{min}$ and $V_{\text {ret }}$ (burner return speed) $1500 \mathrm{~mm} / \mathrm{min}$; and (b) downstream and upstream deposition directions $\left(\mathrm{V}_{\mathrm{dep}} 100 \mathrm{~mm} / \mathrm{min}\right.$ and $\left.\mathrm{V}_{\text {ret }}=\mathrm{V}_{\text {dep }}=100 \mathrm{~mm} / \mathrm{min}\right)$.

The refractive index profiles (RIPs) and longitudinal uniformity of the fabricated preforms were determined using a preform analyzer (Photon Kinetics, P104). The longitudinal uniformity of the fabricated preforms was determined by scanning the preform at $2.0 \mathrm{~cm}$ intervals. For each preform, 
an approximately 3.0-mm-thick disk (with known index difference) was cut from the preform, polished, and subjected to EDX analyses. The EDX analyses were performed using the point identification technique with $10 \times 10$ grid points mapped in each preform's core area and an acquisition time of $240 \mathrm{~s}$ per point. The fabricated preforms were pulled into fibers (125 $\mu \mathrm{m}$ in diameter) using a standard fiber drawing tower and were also subjected to EDX point identification analyses in order to determine the amount and radial distribution of alumina in the core region. The efficiency of the fabrication process was determined by dividing the alumina concentration obtained from EDX analyses by that derived theoretically.

\section{Results and Discussion}

Figure 3 shows the oxidation process of $\mathrm{Al}(\mathrm{acac})_{3}$ at $\mathrm{T}_{\text {dep }} 1850{ }^{\circ} \mathrm{C}$ and an oxygen flow rate of $2400 \mathrm{sccm}$. As the $\mathrm{Al}(\mathrm{acac})_{3}$ vapor passes through the hot zone, alumina particles (soot) are formed and then deposited on the substrate tube wall downstream of the oxyhydrogen burner due to thermophoretic forces. It was observed that the alumina soot was deposited further from the oxyhydrogen burner (i.e., longer taper region). This can be attributed to the high total gas flow rate $\left(Q_{T}\right)$ used during the oxidation process $(3840 \mathrm{sccm})$. The length over which the deposition takes place is proportional to $Q_{T} / \alpha$ [19], where $\alpha$ is the thermal diffusivity. Since the hot zone created by our oxyhydrogen burner is small ( $2 \mathrm{~cm}$ in length), and $Q_{T}$ is high, the residence time of $\mathrm{Al}(\mathrm{acac})_{3}$ inside the hot zone is short. This results in the formation of predominantly fine alumina particles that can be uniformly distributed along the substrate tube. Continuous movement of the hot zone results in fusion of the deposited alumina particles and incorporation into the silica soot. The deposited alumina/silica layers are then vitrified (in oxygen atmosphere) into transparent glassy material.

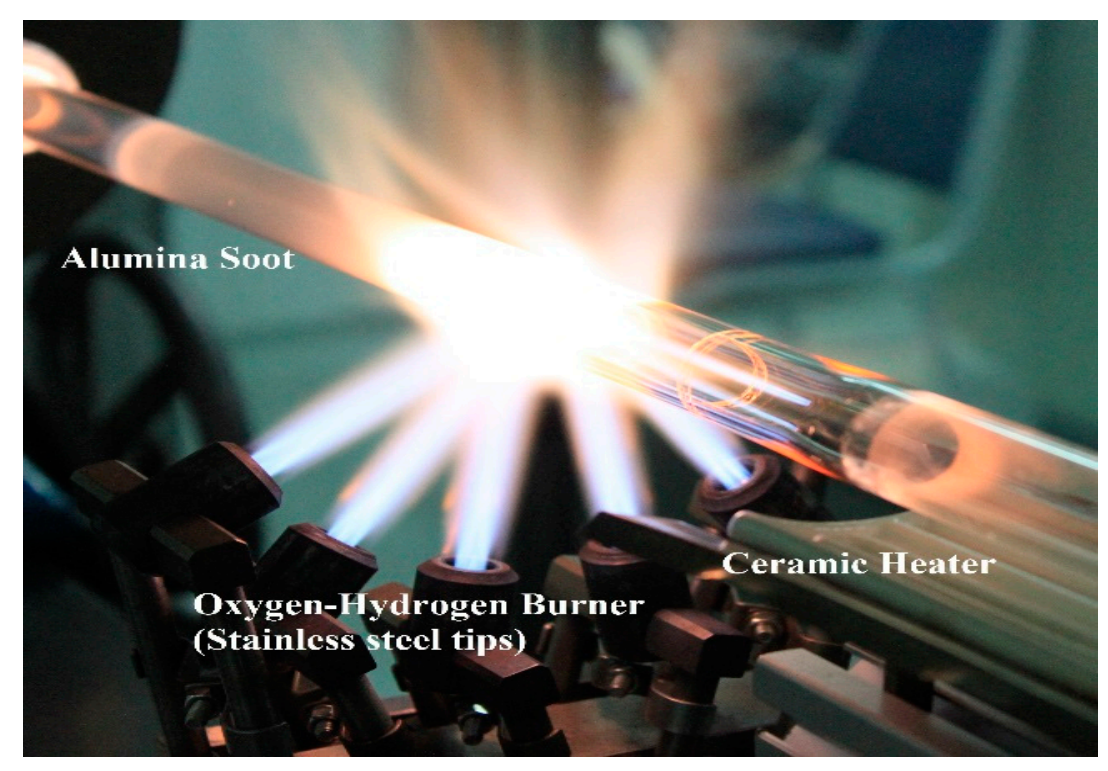

Figure 3. The $\mathrm{Al}(\mathrm{acac})_{3}$ oxidation process via $\mathrm{MCVD}$, where fine white particles (or alumina soot) are deposited along the glass substrate tube while the $\mathrm{Al}(\mathrm{acac})_{3}$ vapor passes through the hot zone. The figure also shows the ceramic heater used to prevent the condensation of $\mathrm{Al}(\mathrm{acac})_{3}$ vapor prior to reaching the hot zone.

Figure $4 \mathrm{a}, \mathrm{b}$ shows the refractive index profiles for $\mathrm{P} 1\left(\mathrm{~T}_{\mathrm{Al}} 175{ }^{\circ} \mathrm{C}\right)$ and $\mathrm{P} 2\left(\mathrm{~T}_{\mathrm{Al}} 185{ }^{\circ} \mathrm{C}\right)$, respectively. Figure $4 \mathrm{c}$,d displays the longitudinal uniformity values of P1 (average $\Delta \mathrm{n}=0.0036$ ) and P2 (average $\Delta \mathrm{n}=0.0124$ ), respectively. As can be seen from the figure, P1 and P2 showed good longitudinal uniformity with a slight variation in the refractive index difference (percent relative standard deviation of index difference (\%RSD) $1 \%$ and $2 \%$, respectively). This good longitudinal uniformity can be ascribed to the high total gas flow rate $\left(Q_{T}\right)$ used and the short hot zone and 
residence time, which result in the production of fine and uniform alumina particles, as discussed above. As is illustrated in Figure $5 \mathrm{a}-\mathrm{d}$, the core $\left(\mathrm{d}_{\text {core }}\right)$ and preform $\left(\mathrm{d}_{\text {preform }}\right)$ diameters for P1 were $1.2 \mathrm{~mm}(\%$ RSD $2.4 \%)$ and $15.0 \mathrm{~mm}$ (\%RSD 1.2\%), respectively, whereas those for P2 were $1.44 \mathrm{~mm}$ (\%RSD $1.4 \%)$ and $15.4 \mathrm{~mm}$ (\%RSD $1.0 \%)$, respectively. This shows that it is possible to fabricate alumina-doped silica preforms with high uniformity of $\Delta \mathrm{n}$ and core size using $\mathrm{Al}(\mathrm{acac})_{3}$ and a chelate vapor delivery system.

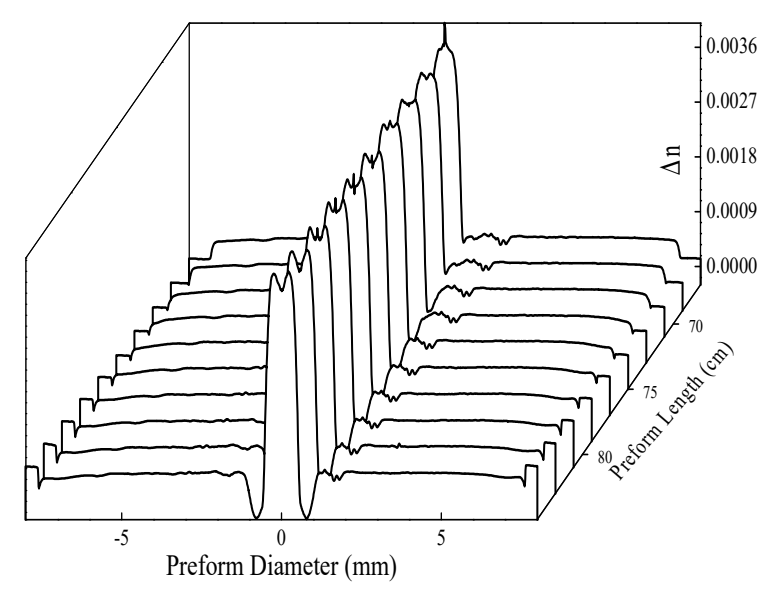

(a)

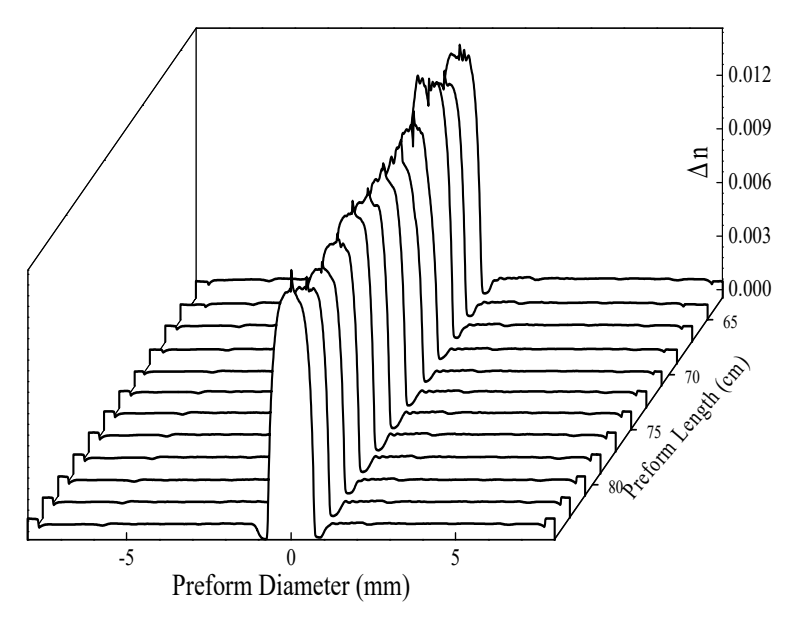

(b)

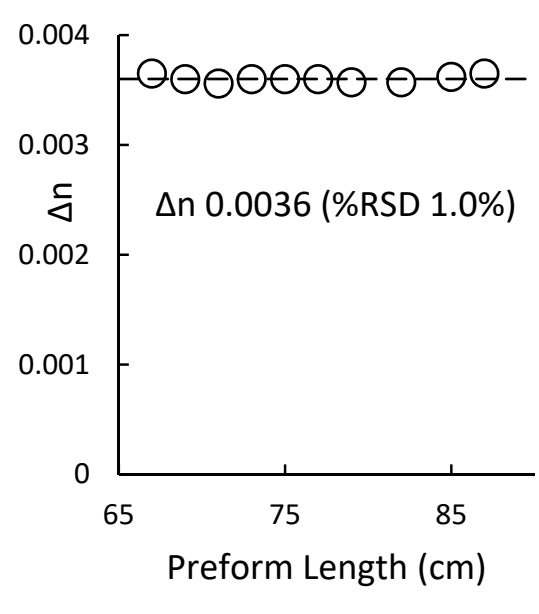

(c)

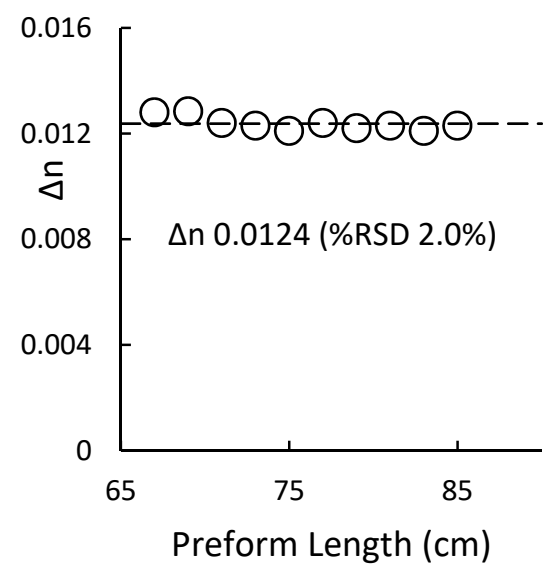

(d)

Figure 4. (a,b) show the refractive index profiles for P1 and P2 along the preform length; (c,d) illustrate the longitudinal variation in the refractive index difference $(\Delta \mathrm{n})$ for P1 and P2, respectively. 


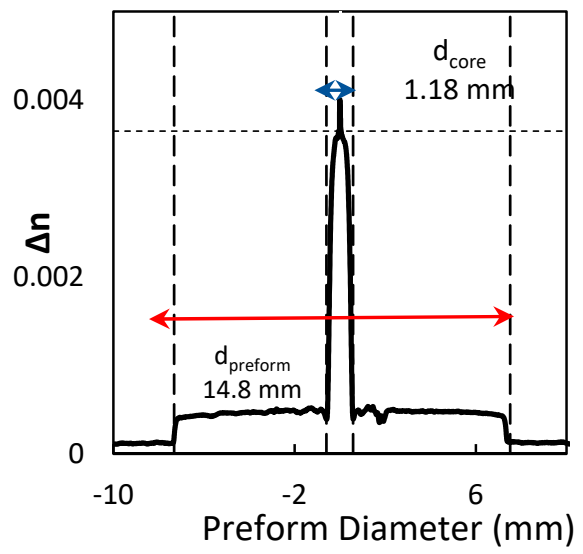

(a)

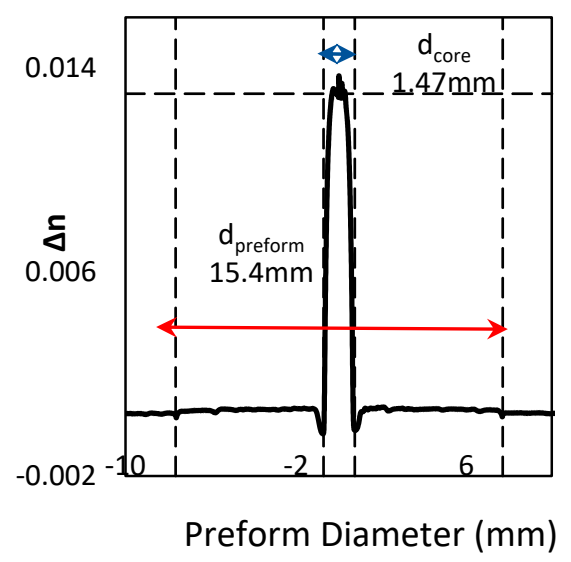

(b)

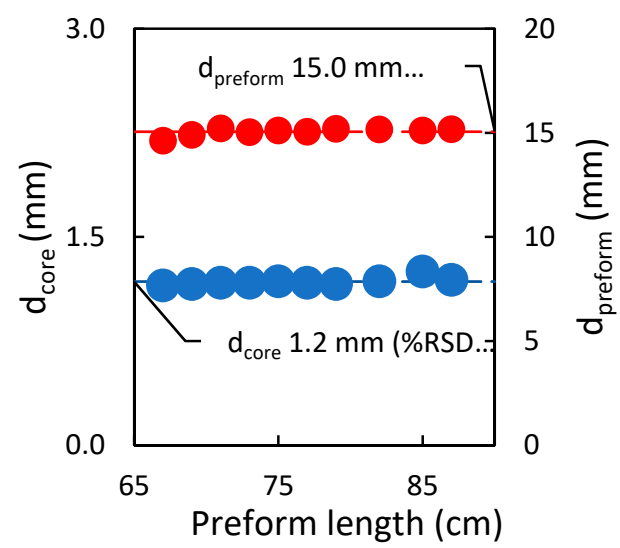

(c)

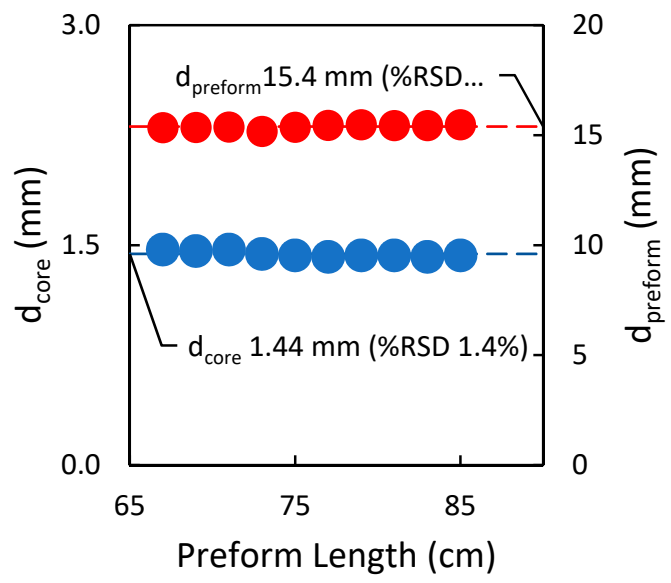

(d)

Figure 5. (a,b) present the refractive index profiles for $\mathrm{P} 1$ and $\mathrm{P} 2$, respectively, obtained at the inlet position and showing the measurements for $\mathrm{d}_{\text {preform }}$ and $\mathrm{d}_{\text {core; }}(\mathbf{c}, \mathbf{d})$ present the longitudinal uniformity of $\mathrm{d}_{\text {preform }}$ and $\mathrm{d}_{\text {core }}$ for $\mathrm{P} 1$ and $\mathrm{P} 2$, respectively.

For preform P3, the deposition of alumina was performed in both the downstream and upstream directions. The upstream deposition mode is normally used to utilize a higher temperature without sintering the produced soot $[20,21]$. In P3, it was observed that the downstream deposition showed the same behavior as P2. In upstream deposition, however, more alumina with large particle size distribution is produced. In this case, the alumina particles are deposited behind the moving burner and are partially sintered since the burner is moving away towards the reactant inlet. In addition, the upstream deposition mode provides higher temperature and a longer hot zone, which, in turn, result in longer residence time and enhanced conversion or oxidation of $\mathrm{Al}(\mathrm{acac})_{3}$. This causes more particle nucleation and agglomeration and, hence, larger particle size distribution in the produced alumina soot [20]. In both P2 and P3, the effect of $Q_{T} / \alpha$ was the same where the length of deposition was observed to be long (i.e., taper region). It is worth mentioning that during the sintering process for P3, a red glow with intensity increasing towards the exhaust tube was observed along the substrate tube (Figure 6a). This is indicative of the high concentration of alumina and was manifest in the collapsed preform where the core had an opaque center stretching from about the middle of the preform to the outlet with increasing opacity towards the outlet (Figure $6 \mathrm{~b}$ ). This may be attributed to the deposition of $\mathrm{Al}_{2} \mathrm{O}_{3}$ in the tiny spaces between silica soot particles. The high temperatures encountered during sintering and collapse may then be enough to cause some aluminum diffusion 
into the silica, thereby producing regions of alumina-rich silicates. The slow cooling of the produced materials as the burner moves away from these regions promotes solidification to a crystalline (rather than an amorphous) phase, causing opacity of the core. Another explanation is the formation of alumina-rich silicates by phase separation and crystallization. This may take place when the binary oxide mixture $\left(\mathrm{Al}_{2} \mathrm{O}_{3} / \mathrm{SiO}_{2}\right)$ encounters a suitable temperature during sintering or collapse, provided that the aluminum concentration is high enough [22].

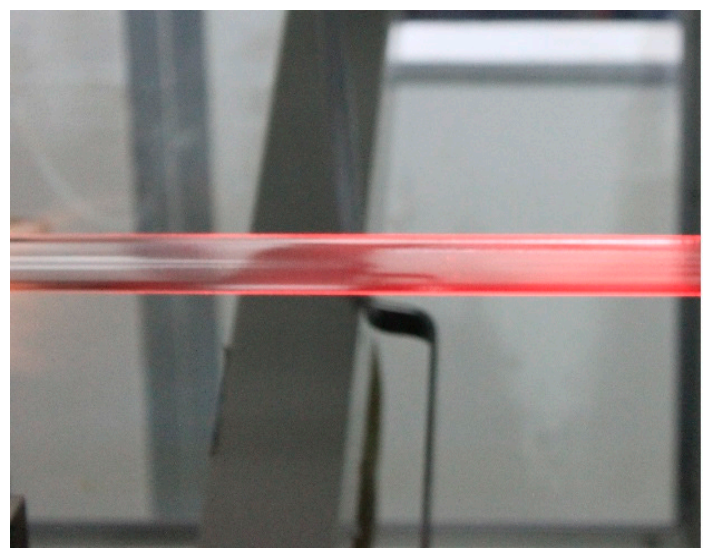

(a)

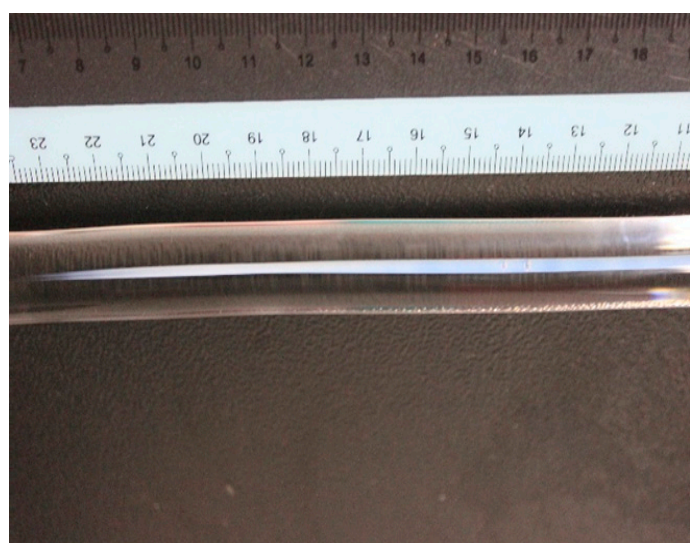

(b)

Figure 6. (a) P3 sintering process with an oxygen flow rate of $1000 \mathrm{sccm}$, temperature of $2000-2100{ }^{\circ} \mathrm{C}$, and $V_{b}$ of $125 \mathrm{~mm} / \mathrm{min}$. The red glow is an indicator of the high alumina content in the preform. (b) shows the opaque regions in the core due to the presence of Al-rich aluminosilicate crystallites.

It should be pointed out that even though the upstream deposition yielded more alumina, the uniformity in the longitudinal refractive index difference significantly deteriorated. However, the uniformity could be improved with a cooling mechanism, as reported by Bubnov et al. [23]. Figure 7a illustrates the refractive index profile for $\mathrm{P} 3$. The variation in the longitudinal refractive index difference is rather small along the first $13 \mathrm{~cm}$ from the inlet (\%RSD $4 \%$, Figure $7 \mathrm{~b}$ ). It is, however, significantly high along the full length of the preform. The highest core-to-cladding refractive index difference was found to be 0.027 and was for the region of the preform adjacent to the outlet. It was noticed that the opacity in the core was pronounced when the core-to-cladding refractive index difference was greater than $0.015\left(\sim 6 \mathrm{~mol} . \% \mathrm{Al}_{2} \mathrm{O}_{3}\right)$. This is consistent with the conclusion that the opaque regions in the core of the preform are attributable to the formation of Al-rich aluminosilicate crystalline phase. One possible aluminosilicate crystalline phase is mullite $\left(3 \mathrm{Al}_{2} \mathrm{O}_{3} \cdot 2 \mathrm{SiO}_{2}\right)$. X-ray diffraction and Raman spectroscopy analyses carried out by Abramov et al. [24] indicated that high-temperature annealing of aluminosilicate fibers and preforms gives rise to the formation of crystalline mullite phase. It should be mentioned that a rapid cooling rate may prevent crystallization in the core of the preform, although such a rate is typically much higher than that achieved during the MCVD process.

The energy-dispersive X-ray spectroscopy (EDX) method was used to investigate the Al distribution and content across the core of the preforms and fibers. The EDX point identification analyses were carried out to support and complement the afore-discussed refractive index profile results. The EDX results for preform P3 are illustrated in Figure 8a,b. As can be seen from Figure 8a, the Al distribution across the core region is uniform and matches the RIP where the Al content gradually increases, reaches a maximum, and then gradually decreases. The $\mathrm{Al}$ concentration is highest in the center of the core and was found to range from 8.6 to $9.9 \mathrm{wt} . \%$. 


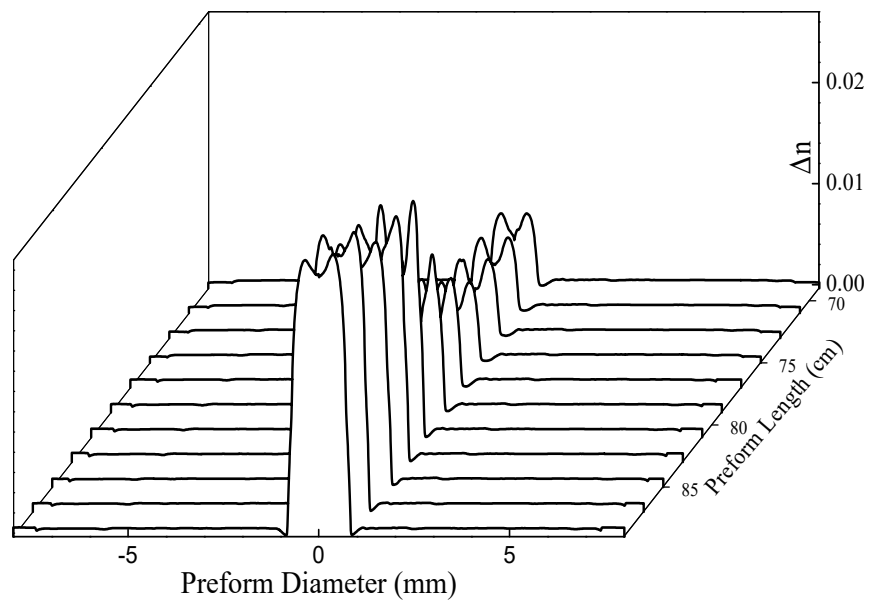

(a)

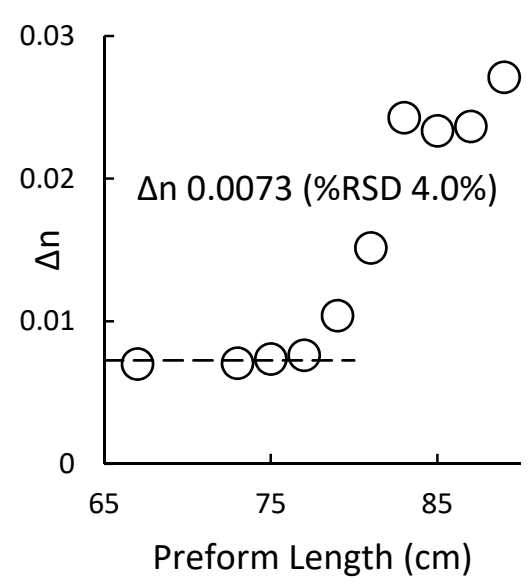

(b)

Figure 7. (a) The refractive index profile and (b) the longitudinal variation in the refractive index difference $(\Delta \mathrm{n})$ for preform $\mathrm{P3}$.

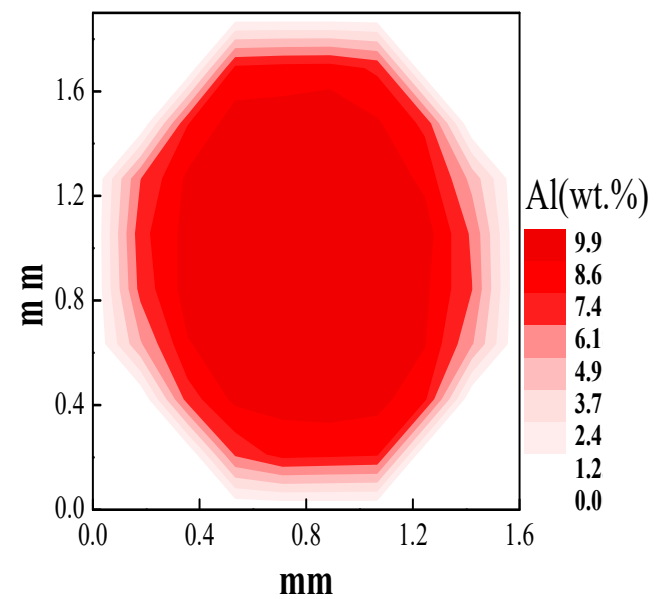

(a)

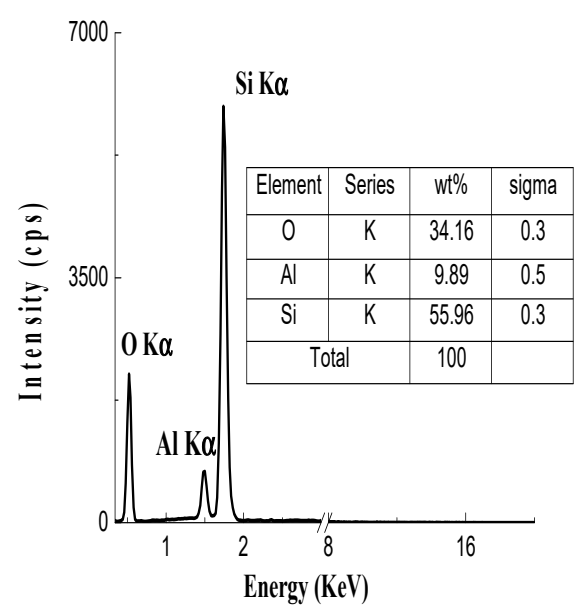

(b)

Figure 8. (a) A contour plot of the Al concentration in the core region of preform P3. The EDX point identification measurements were performed for $10 \times 10$ grid points covering an area of $2.0 \times 2.0 \mathrm{~mm}$. The sample for EDX analysis was cut from the edge of the preform adjacent to the outlet. (b) The EDX spectrum measured at the point with the highest $\mathrm{Al}$ concentration $(9.9 \mathrm{wt} . \%)$. The inset table lists the wt.\% of $\mathrm{Al}, \mathrm{Si}$, and $\mathrm{O}$.

Figure 9a-c shows contour plots of the Al distribution for fibers F1, F2, and F3, respectively, that were drawn from preforms P1, P2, and P3, respectively. In general, the Al distributions for all fibers show the same pattern, with the highest $\mathrm{Al}$ content being located at the center of the core area. The maximum Al concentrations for fibers F1, F2, and F3 were 1.7, 4.3, and 3.2 wt.\%, respectively. This corresponds to alumina concentrations of $1.9,4.9$, and 3.7 mole\% for F1, F2, and F3, respectively. In the current study, the fabrication process efficiency was measured by dividing the alumina content obtained from EDX analyses of fibers by that derived theoretically. For the fabricated fibers F1 and F2, the process efficiency values were found to be 11 and $21 \%$, respectively. These values indicate that the 
$\mathrm{T}_{\mathrm{Al}}{ }^{\circ} \mathrm{C}$ is a critical factor; an increase in $\mathrm{T}_{\mathrm{Al}}{ }^{\circ} \mathrm{C}$ of $10{ }^{\circ} \mathrm{C}$ resulted in a 3.3-fold increase in $\mathrm{Al}_{2} \mathrm{O}_{3}$ content. The relationship between $\Delta \mathrm{n}$ (obtained from RIP) and $\mathrm{Al}_{2} \mathrm{O}_{3}$ mol.\% (obtained from EDX analysis) is plotted in Figure 10. As can be observed from the figure, the refractive index of silica increased by 0.0025 per $\mathrm{mol} \%$ of $\mathrm{Al}_{2} \mathrm{O}_{3}$. This is in line with the results obtained by Bubnov et al. [25], where the authors used an MCVD vapor phase technique with $\mathrm{AlCl}_{3}$ as the precursor.

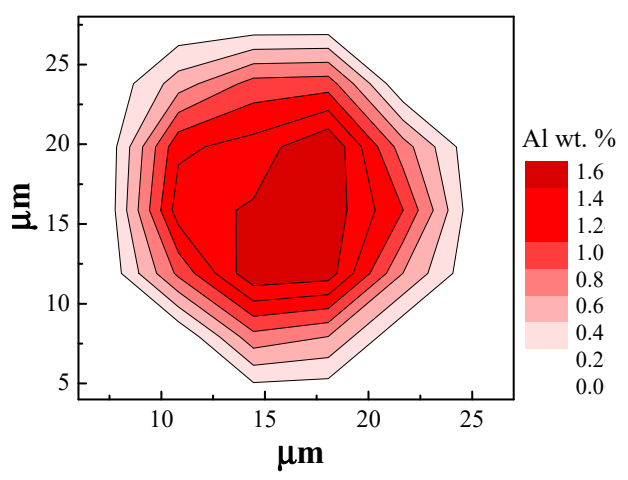

\begin{tabular}{lcccc}
\hline & wt.\% & $\sigma$ wt.\% & mole\% & \\
\hline $\mathrm{Si}$ & 45.28 & 0.4 & $\mathrm{SiO}_{2}$ & 98.1 \\
$\mathrm{O}$ & 53.06 & 0.3 & & \\
$\mathrm{Al}$ & 1.66 & 0.09 & $\mathrm{Al}_{2} \mathrm{O}_{3}$ & 1.9 \\
\hline
\end{tabular}

(a)

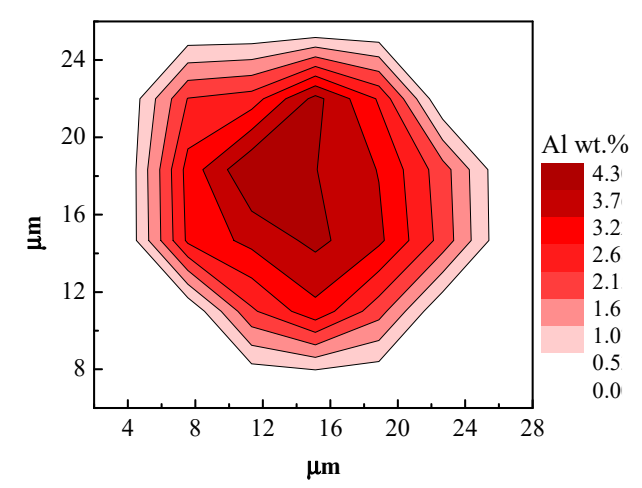

\begin{tabular}{llcll}
\hline & wt.\% & $\sigma$ wt.\% & mole\% & \\
\hline $\mathrm{Si}$ & 42.95 & 0.5 & $\mathrm{SiO}_{2}$ & 95.1 \\
$\mathrm{O}$ & 52.75 & 0.3 & & \\
$\mathrm{Al}$ & 4.30 & 0.1 & $\mathrm{Al}_{2} \mathrm{O}_{3}$ & 4.9 \\
\hline
\end{tabular}

(b)

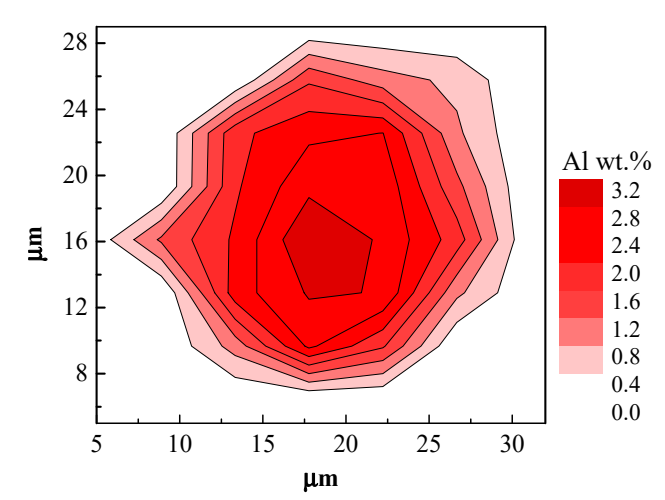

\begin{tabular}{crcll}
\hline & wt.\% & $\sigma$ wt.\% & mole\% & \\
\hline $\mathrm{Si}$ & 43.9 & 0.5 & $\mathrm{SiO}_{2}$ & 96.3 \\
$\mathrm{O}$ & 52.8 & 0.4 & & \\
$\mathrm{Al}$ & 3.22 & 0.1 & $\mathrm{Al}_{2} \mathrm{O}_{3}$ & 3.7 \\
\hline
\end{tabular}

(c)

Figure 9. Contour plots of $\mathrm{Al}$ distribution across the core of fibers (a) F1, (b) F2, and (c) F3. The highest $\mathrm{Al}$ concentrations detected in F1, F2, and F3 were 1.7, 4.3, and $3.2 \mathrm{wt}$ \%, respectively. The corresponding concentrations of $\mathrm{Al}_{2} \mathrm{O}_{3}$ were 1.9, 4.9, and 3.7 mole\% for fibers $\mathrm{F} 1, \mathrm{~F} 2$, and F3, respectively. 


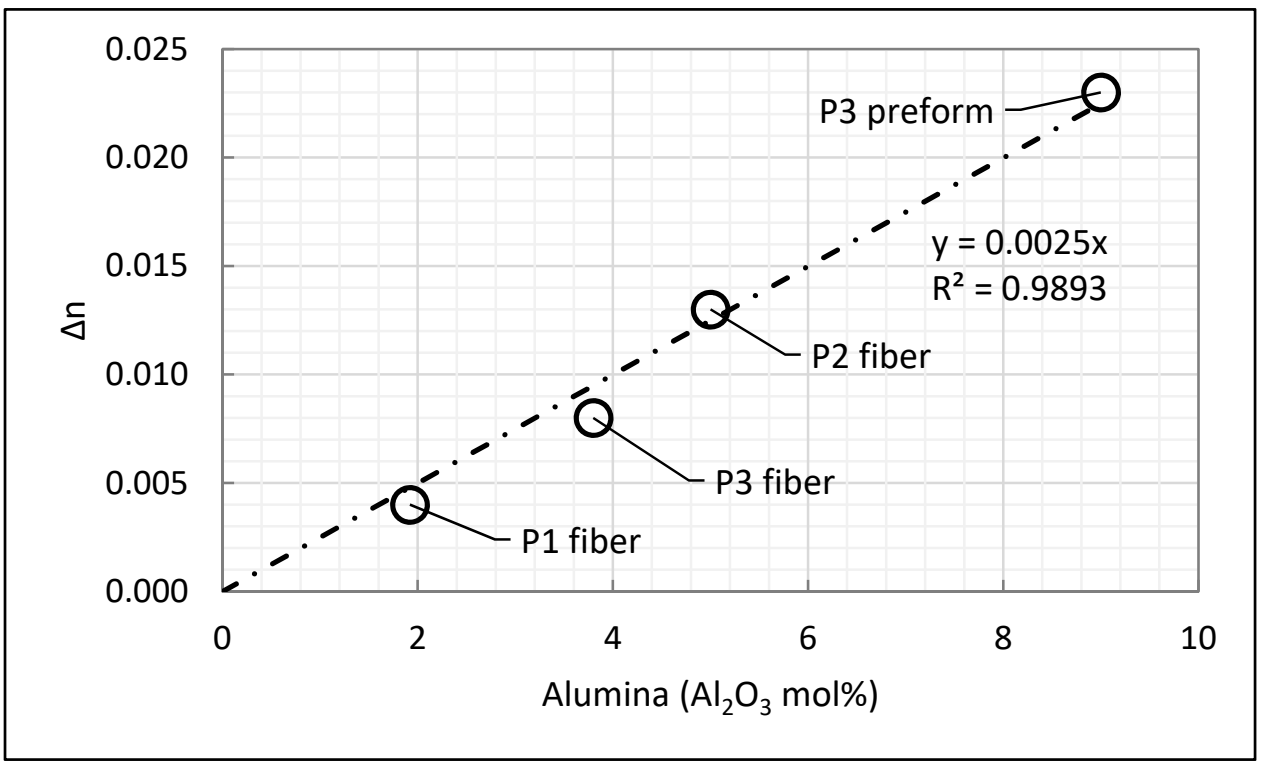

Figure 10. Plot of the refractive index difference vs. mol\% of alumina in the range of 0 to $9 \mathrm{~mol} \%$. The refractive index of silica increases by 0.0025 per $\mathrm{mol} \%$ of $\mathrm{Al}_{2} \mathrm{O}_{3}$.

\section{Conclusions}

Herein, we reported an initial study on alumina-doped silica preforms/fibers fabricated by an MCVD vapor phase technique using $\mathrm{Al}(\mathrm{acac})_{3}$ as the precursor. The study, to the best of our knowledge, indicates the highest possible concentration of $\mathrm{Al}_{2} \mathrm{O}_{3}$ using this approach. The $\mathrm{Al}(\mathrm{acac})_{3}$ sublimation temperature and the deposition direction (i.e., downstream and upstream) were varied while keeping other parameters, such as oxygen flow rate and deposition temperature, fixed. At a sublimation temperature of $185^{\circ} \mathrm{C}$, the process efficiency was found to be $21 \%$. For the downstream deposition, the longitudinal uniformity for $\Delta \mathrm{n}$ and core size was observed to be significantly higher than that for the combined downstream/upstream deposition (\%RSD values for $\Delta \mathrm{n}$ and core size of $<2 \%$ and $<2.4 \%$, respectively, vs. $55 \%$ and $18 \%$, respectively). We also reported on the refractive index change per $\mathrm{mol} \%$ of $\mathrm{Al}_{2} \mathrm{O}_{3}$, which was found to be 0.0025 . The optical and spectroscopic properties of the fabricated fibers are currently being thoroughly studied by our group.

Author Contributions: Conceptualization, K.A.M.S., N.Y.M.O., and H.A.A.-R.; methodology and investigation, K.A.M.S., N.Y.M.O., M.I.Z., and S.Z.M.Y.; data curation and analysis, K.A.M.S., M.I.Z., and S.Z.M.Y.; data validation, N.Y.M.O. and H.A.A.-R.; writing—original draft preparation, K.A.M.S.; writing-review and editing, N.Y.M.O., M.I.Z., S.Z.M.Y., and H.A.A.-R.; supervision, H.A.A.-R.; project administration, N.Y.M.O.; funding acquisition, H.A.A.-R. All authors have read and agreed to the published version of the manuscript.

Funding: The authors would like to thank Telekom Malaysia through its R \& D subsidiary (TMR \& D) for supporting this project.

Conflicts of Interest: The authors declare no conflict of interest.

\section{References}

1. Maurer, R.D.; Schultz, P.C. Fused Silica Optical Waveguide. U.S. Patent No. 3659915, 2 May 1972.

2. Simpson, J.R.; Macchesney, J.B. Alternate Dopants for Silicate Wave-Guides. In Proceedings of the Optical Fiber Communication; Optical Society of America: Washington, DC, USA, 1982; p. TuCC5. [CrossRef]

3. Ohmori, Y.; Miya, T.; Horiguchi, M. Transmission-Loss Characteristics of $\mathrm{Al}_{2} \mathrm{O}_{3}$-Doped Silica Fibers. J. Lightw. Technol. 1983, 1, 50-56. [CrossRef]

4. Roba, G. Method of Fabricating Alumina-Doped Silica Fibers. U.S. Patent No. 4657575, 14 April 1987. 
5. Wang, J.; Li, M.-J.; Nolan, D.A. The Lowest-Loss of 0.35 dB/km in an Aluminum-Doped SM Optical Fiber. In Proceedings of the 2006 Optical Fiber Communication Conference and the National Fiber Optic Engineers Conference, Anaheim, CA, USA, 5-10 March 2006; p. 3. [CrossRef]

6. Wang, J. Alumina as a Dopant in Optical Fiber by OVD. Appl. Phys. A 2014, 116, 505-518. [CrossRef]

7. Čampelj, S.; Perpar, L.; Lukan, P.; Štajner, J.; Ramšak, A.; Lenardič, A.; Lenardič, B. Background Attenuation of Al-Doped Fibers Produced with Vapor Phase Doping Technique. In Proceedings of the Workshop on Specialty Optical Fibers and Their Applications; Optical Society of America: Washington, DC, USA, 2015; p. WT4A.8. [CrossRef]

8. Muhd-Yassin, S.Z.; Omar, N.Y.M.; Mat-Sharif, K.A.; Zulkifli, M.I.; Safar, M.H.; Aljamimi, S.M.; Yusoff, Z.; Emami, S.D.; Paul, M.C.; Abdul-Rashid, H.A. Solution Doped Preform with Improved Uniformity and Concentration Using Dual-Layer Soot Deposition. Opt. Fiber Technol. 2016, 28, 23-27. [CrossRef]

9. Tumminelli, R.P.; McCollum, B.C.; Snitzer, E. Fabrication of High-Concentration Rare-Earth Doped Optical Fibers Using Chelates. J. Lightw. Technol. 1990, 8, 1680-1683. [CrossRef]

10. Lenardic, B.; Guillon, H.; Bonnafous, S.; Kveder, M. Fabrication of Rare-Earth Doped Fibers by Flash Vaporization Method. In Proceedings of the 33rd European Conference and Exhibition of Optical Communication, Berlin, Germany, 16-20 September 2007; pp. 1-2. [CrossRef]

11. Sekiya, E.H.; Barua, P.; Saito, K.; Ikushima, A.J. Fabrication of Yb-Doped Silica Glass through the Modification of MCVD Process. J. NonCryst. Solids 2008, 354, 4737-4742. [CrossRef]

12. Unger, S.; Lindner, F.; Aichele, C.; Leich, M.; Schwuchow, A.; Kobelke, J.; Dellith, J.; Schuster, K.; Bartelt, H. A Highly Efficient Yb-Doped Silica Laser Fiber Prepared by Gas Phase Doping Technology. Laser Phys. 2014, 24, 035103. [CrossRef]

13. Anuar, K.M.S.; Muhd-Yasin, S.Z.; Zulkifli, M.I.; Hanif, S.; Yusoff, A.; Aljamimi, S.M.; Zubair, H.T.; Yusoff, Z.; Abdul-Rashid, H.A.; Tamchek, N. $\mathrm{Er}_{2} \mathrm{O}_{3}-\mathrm{Al}_{2} \mathrm{O}_{3}$ Doped Silica Preform Prepared by MCVD-Chelate Vapor Phase Delivery Technique. Adv. Mater. Res. 2014, 896, 219-224. [CrossRef]

14. Mat-Sharif, K.A.; Omar, N.Y.M.; Hanif, S.; Zulkifli, M.I.; Muhamad-Yassin, S.Z.; Yusoff, A.; Zubair, H.T.; Aljamimi, S.M.; Yusoff, Z.; Abdul-Rashid, H.A.; et al. Fabrication of $\mathrm{Tm}_{2} \mathrm{O}_{3} / \mathrm{Al}_{2} \mathrm{O}_{3}$-Silica Preform by Improved MCVD-Chelate Delivery System. In Proceedings of the 2014 IEEE 5th International Conference on Photonics (ICP), Pattaya, Thailand, 28-31 July 2014; pp. 119-122. [CrossRef]

15. Saha, M.; Pal, A.; Pal, M.; Guha, C.; Sen, R. An Optimized Vapor Phase Doping Process to Fabricate Large Core Yb-Doped Fibers. J. Lightw. Technol. 2015, 33, 3533-3541. [CrossRef]

16. Wang, Z.; Zhan, H.; Ni, L.; Peng, K.; Wang, X.; Wang, J.; Jing, F.; Lin, A. Research Progress of Chelate Precursor Doping Method to Fabricate Yb-Doped Large-Mode-Area Silica Fibers for KW-Level Laser. Laser Phys. 2015, 25, 115103. [CrossRef]

17. Mat-Sharif, K.A.; Omar, N.Y.M.; Zulkifli, M.I.; Muhd-Yassin, S.Z.; Sin, Y.K.; Abdul-Rashid, H.A.; Tamchek, N. Highly Tm Doped Silica Optical Preform by MCVD-Chelate Vapor Delivery (Soot-Dopant Stepwise Technique). Key Eng. Mater. 2018, 780, 57-61. [CrossRef]

18. Semyannikov, P.P.; Igumenov, I.K.; Trubin, S.V.; Chusova, T.P.; Semenova, Z.I. Thermodynamics of Sublimation of Aluminium Triacetylacetonate. Thermochim. Acta 2006, 451, 80-83. [CrossRef]

19. Walker, K.L.; Geyling, F.T.; Nagel, S.R. Thermophoretic Deposition of Small Particles in the Modified Chemical Vapor Deposition (MCVD) Process. J. Am. Ceram. Soc. 1980, 63, 552-558. [CrossRef]

20. Tang, F.Z.; McNamara, P.; Barton, G.W.; Ringer, S.P. Nanoscale Characterization of Silica Soots and Aluminium Solution Doping in Optical Fibre Fabrication. J. NonCryst. Solids 2006, 352, 3799-3807. [CrossRef]

21. Krichhof, J.; Unger, S.; Grau, L.; Funke, A.; Kleinert, P. A New MCVD Technique for Increased Efficiency of Dopant Incorporation in Optical Fibre Fabrication. Cryst. Res. Technol. 1990, 25, K29-K34. [CrossRef]

22. Tang, F.Z.; McNamara, P.; Barton, G.W.; Ringer, S.P. Multiple Solution-Doping in Optical Fibre Fabrication I-Aluminium Doping. J. NonCryst. Solids 2008, 354, 927-937. [CrossRef]

23. Bubnov, M.M.; Gur'yanov, A.N.; Salganskii, M.Y.; Khopin, V.F. Reaction of Germanium Tetrachloride with Oxygen under MCVD Fiber Preform Fabrication Conditions. Inorg. Mater. 2007, 43, 968-971. [CrossRef] 
24. Abramov, A.N.; Yashkov, M.V.; Guryanov, A.N.; Melkumov, M.A.; Dvoretskii, D.A.; Bufetov, I.A.; Iskhakova, L.D.; Koltashev, V.V.; Kachenyuk, M.N.; Torsunov, M.F. Fabrication and Optical Characterization of Silica Fibers with a Chromium- and Alumina-Doped Core. Inorg. Mater. 2014, 50, 1283-1288. [CrossRef]

25. Bubnov, M.M.; Gur'yanov, A.N.; Zotov, K.V.; Iskhakova, L.D.; Lavrishchev, S.V.; Lipatov, D.S.; Likhachev, M.E.; Rybaltovsky, A.A.; Khopin, V.F.; Yashkov, M.V.; et al. Optical Properties of Fibres with Aluminophosphosilicate Glass Cores. Quantum Electr. 2009, 39, 857-862. [CrossRef]

Publisher's Note: MDPI stays neutral with regard to jurisdictional claims in published maps and institutional affiliations.

(C) 2020 by the authors. Licensee MDPI, Basel, Switzerland. This article is an open access article distributed under the terms and conditions of the Creative Commons Attribution (CC BY) license (http://creativecommons.org/licenses/by/4.0/). 